\title{
Editorial Expression of Concern: "[1] Kumar, A., Ekavali, Mishra, J. et al. Possible role of P-glycoprotein in the neuroprotective mechanism of berberine in intracerebroventricular streptozotocin-induced cognitive dysfunction. Psychopharmacology 233, 137-152 (2016)"
}

Published online: 4 August 2020

(C) Springer-Verlag GmbH Germany, part of Springer Nature 2020

The Editor-in-Chief would like to alert readers that concerns have been raised regarding the data in this article [1]. The biochemical indices are almost perfectly correlated with the behavioural variables suggesting that either the behaviour is completely determined by nitrite and lipid peroxidation or that there are problems with the data. In addition to this, the standard errors for all variables are suspiciously low based on other typical variance found in the published literature. Currently the authors are unable to recover the raw data due to national lockdown related to Covid-19. Further editorial action may be taken following the analysis of the raw data or request of further institutional investigation. In the meantime readers are advised to interpret the results with caution. Anil Kumar has not responded to any correspondence from the editor/publisher about this editorial expression of concern.

Publisher's note Springer Nature remains neutral with regard to jurisdictional claims in published maps and institutional affiliations. 